\title{
Association of Chorioamnionitis With Failed Conversion of Epidural Labor Analgesia to Cesarean Delivery Anesthesia: a Retrospective Cohort Study
}

\section{Yumi Katakura}

Yokohama City University Hospital

Yusuke Nagamine ( $\nabla$ ynagamin@yokohama-cu.ac.jp )

Yokohama City University https://orcid.org/0000-0002-0443-5007

Takahisa Goto

Yokohama City University Hospital

Hiroyuki Sumikura

Juntendo University Hospital

Research article

Keywords: chorioamnionitis, failed anesthesia for cesarean sections, the control of epidural labor analgesia

Posted Date: August 13th, 2020

DOl: https://doi.org/10.21203/rs.3.rs-52560/v1

License: (c) (i) This work is licensed under a Creative Commons Attribution 4.0 International License. Read Full License

Version of Record: A version of this preprint was published at PLOS ONE on May 5th, 2021. See the published version at https://doi.org/10.1371/journal.pone.0250596. 


\section{Abstract}

Background: This study examined the association between clinically diagnosed chorioamnionitis and failed conversion of epidural labor analgesia to cesarean delivery anesthesia.

Methods: This retrospective cohort study, conducted in a single-center university hospital, enrolled term parturients undergoing emergency cesarean section after induction of epidural labor analgesia between September 2015 and May 2019. For the purpose of the study, all cases were re-examined to ensure that they fulfilled the criteria of chorioamnionitis, regardless of the actual indication for cesarean section proposed by obstetricians at the time of application. The primary outcome was failure of conversion of epidural labor analgesia to cesarean delivery anesthesia. Multivariable logistic regression analysis was performed to investigate the association between chorioamnionitis and failure of anesthesia for cesarean section.

Results: Among the 180 parturients, it was found that 58 parturients (43.9\%) fulfilled the criteria of chorioamnionitis. Failure of epidural conversion in the chorioamnionitis (+) group was significantly higher than that in the chorioamnionitis (-) group (46.6\% [27/58] vs. $18.9 \%$ [14/74], crude odds ratio $=3.7,95 \%$ confidence interval 1.7-8.3). After adjustment for potential confounders (age, body mass index, multiparity, and duration for epidural labor analgesia), chorioamnionitis was found to be associated with failure of anesthesia for cesarean sections (adjusted odds ratio $=3.6,95 \%$ confidence interval 1.6-8.4).

Conclusions: Chorioamnionitis is associated with the failed conversion of epidural labor analgesia to cesarean delivery anesthesia.

\section{Introduction}

Epidural labor analgesia is widely practiced all over the world, and more than $70 \%$ of pregnant women opt for it in the USA [1]. However, it is reported that $4-14 \%$ of them need cesarean sections after induction of epidural labor analgesia [2]. When an emergency cesarean section is proposed for a parturient who is receiving epidural labor analgesia, epidural analgesia can be converted to operative anesthesia by injecting local anesthetics through the existing epidural catheter. This process is often referred to as epidural conversion [3], and it is thought to be an advantage of having epidural labor analgesia. In the case of failed epidural conversion, however, general or spinal anesthesia may be required. Therefore, the risk factors of failed conversion of epidural labor analgesia to cesarean delivery anesthesia have been widely studied [3-10].

Chorioamnionitis (CAM), a common indication of emergency cesarean section during labor, is an infection of the chorion, amnion, or both, and it activates the maternal and fetal inflammatory response systems. Therefore, it is thought that activation of the inflammatory response may lead to increased activation of pain during labor and may cause difficulty in achieving adequate labor analgesia and operative anesthesia in patients with CAM. However, the association between CAM and failed conversion of epidural labor analgesia to cesarean delivery anesthesia has not been studied. 
The objective of this retrospective cohort study is to examine the association between CAM and failed conversion of epidural labor analgesia to cesarean delivery anesthesia.

\section{Methods}

\section{Design, setting}

This single-center, retrospective cohort study was conducted in Juntendo University Hospital, a teaching hospital in where 1200 deliveries, including 850 deliveries receiving epidural labor analgesia, are carried out annually. We collected data from medical records, anesthetic records, labor analgesia records, and partographs.

\section{Participants}

From September 2015 to May 2019, term parturients who were aged $>20$ years and who underwent cesarean sections while receiving labor analgesia were enrolled in this study. We excluded those parturients who required stat cesarean sections (category 1, NICE classification [11]), those who underwent surgery within $2 \mathrm{~h}$ of induction of epidural labor analgesia, and those who were not given any local anesthetics via epidural catheter because of the subjective definition of the anesthesiologist to choose an alternate anesthetic route to provide operative anesthesia.

\section{Standard protocol for labor epidural analgesia}

Although this study was performed as a retrospective one, our standard protocol for labor analgesia and anesthetic management of cesarean section for parturient after induction of labor analgesia were as follows. During the study period, all case was managed under the supervision of our senior staff. Obstetric anesthesiologists performed all the anesthetic procedures in this study. The standard ways of induction of labor analgesia are combined spinal and epidural anesthesia (CSEA), dural puncture epidural (DPE), or epidural anesthesia (EPI). Anesthesiologists decided which ways to perform as the initial technique. Labor analgesia was initiated to all women upon request, regardless of the degree of cervical dilation. For induction of CSEA, $10 \mu \mathrm{g}$ of fentanyl and $2.5 \mathrm{mg}$ of bupivacaine were administered intrathecally via the L3-L4 interspace. Then, an epidural catheter was placed by needle through needle technique. The DPE technique is a modification of the CSEA technique, where a dural perforation is created with a spinal needle, but intrathecal medication is withheld [12]. For induction of EPI and DPE, levobupivacaine $(0.125 \%)$ with fentanyl $(5 \mu \mathrm{g} / \mathrm{mL})$ was administered incrementally $(10-20 \mathrm{ml})$. For maintenance of labor analgesia, $0.1 \%$ ropivacaine or $0.08 \%$ levobupivacaine, with fentanyl $(2 \mu \mathrm{g} / \mathrm{mL})$ was administered using a patient-controlled epidural analgesia (PCEA) device regardless of the induction technique. Settings for PCEA were a bolus dose of $5 \mathrm{ml}$, a lockout time of $15 \mathrm{~min}$, and no background infusion. Pain intensity was measured using numerical rating scales of 0 to 10 points $(0=$ no pain, $10=$ worst pain). Scores of $\leq 4$ were considered to be adequate pain relief. Anesthesiologists checked for the adequate block every one to two hours during labor analgesia, even with PCEA. When cesarean 
section was decided, $10 \mathrm{ml}$ of $2 \%$ lidocaine, $1 \mathrm{ml}$ of $7 \%$ bicarbonate were administered, and another $5 \mathrm{ml}$ of $2 \%$ lidocaine with 100 micrograms of fentanyl was added when needed.

\section{Exposure}

All cases during the studying period were examined if it fulfilled the criteria of chorioamnionitis, regardless of the proposed indication for cesarean section for the purpose of this study. We defined CAM as suspected Triple I [13] (intrauterine infection or inflammation or both) (Additional Table 1). The criteria are as follows.

Fever without a clear source plus any of the following

- baseline fetal tachycardia (>160 bpm) for 10 minutes or longer, excluding accelerations, decelerations and periods of marked variability

- maternal WBC > 15,000 per $\mathrm{mm}^{3}$ in the absence of corticosteroids

- definite purulent fluid from the cervical os

We collected laboratory data, symptoms, and vital signs from delivery records and electronic medical records, and the parturients whose data were complete for the criteria were classified into CAM (+) group. All the parturients were retrospectively classified into CAM (+) or CAM (-) group.

\section{Outcome}

The primary outcome was failure of conversion of epidural labor analgesia to cesarean delivery anesthesia. We defined this failure as the inability of anesthesiologists to provide adequate anesthesia until the end of surgery using only local anesthetics via the epidural catheter inserted for epidural labor analgesia and/or the need to administer a sedative agent or intravenous analgesics.

The secondary outcomes included the following variables regarding labor analgesia; the number of PCEA request that parturient pushed the PCEA button, number of PCEA bolus, hourly consumption of PCEA solution, and the number of rescue by an anesthesiologist. In addition, we checked the intervertebral range of 'loss of cold' level from L3/4.

\section{Covariates}

We listed age, body mass index (BMI), whether the patient was parous or not, and the duration between the induction of labor analgesia and entry into the operating room as potential confounders.

The degree of urgency and the type of anesthesia are considered potential effect modifiers. We exclude the cases of stat cesarean section (category 1 of the NICE classification); therefore, the degree of urgency was unified. The types of anesthesia were divided into subgroups (CSEA or non CSEA). Non CSEA subgroup was small to analyze; therefore, the results of CSEA subgroup analysis is shown as Additional 
Tables. We categorized some quantitative variables, age, BMI, and duration of anesthesia, into some groups in analyzing.

\section{Statistical analysis}

Statistical analysis was performed with JMP software package (JMP 12 pro; SAS Inc., Cary, NC, USA). The results were expressed as median (interquartile range; IQR) or count (\%). Univariate analysis was performed by the $\chi^{2}$ test or Fisher's exact test for categorical variables and Wilcoxon rank-sum test for continuous variables. Multivariable logistic regression was used to estimate multivariable-adjusted odds ratios and $95 \%$ confidence intervals $(\mathrm{Cl})$. The multivariable analysis was adjusted for age, $\mathrm{BMI}$, multiparity, and duration for epidural labor analgesia. We considered the type of anesthesia as an effect modifier and analyzed the association between factors and outcomes as a subgroup analysis. Statistical significance was set at two-tailed $p$ values less than 0.05 .

\section{Results}

The study flow diagram is shown in Figure 1. During the study period, 180 parturients were enrolled. We excluded 10 parturients who underwent stat cesarean section (category 1). Twenty-four parturients were excluded who underwent cesarean section within $2 \mathrm{~h}$ after induction of labor analgesia, along with 14 who were anesthetized for the operation without adding any local anesthetics via epidural catheter because of an unreliable epidural catheter. The remaining 132 women were analyzed for this study. They received cesarean sections due to non-reassuring fetal status or arrest of labor.

Table 1. Baseline characteristics of the study population 


\begin{tabular}{|llll|}
\hline Table 1 & & & \\
\hline & CAM (-) & CAM (+) & $\mathrm{p}$ value \\
\hline Maternal age & $\mathrm{n}=74$ & $\mathrm{n}=58$ & \\
\hline$<35$ & $37(33-40)$ & $35(34-39)$ & $\mathrm{p}=0.53$ \\
\hline 35 to $<45$ & $24[32.4]$ & $17[29.3]$ & \\
\hline $45 \geq$ & $49[66.2]$ & $40[69.0]$ & \\
\hline Parous woman & $1[1.4]$ & $1[1.7]$ & $\mathrm{p}=0.86$ \\
\hline Gestational age (wk) & $3[4.1]$ & $2[3.4]$ & $\mathrm{p}=0.14$ \\
\hline Height (cm) & $40(39-41)$ & $40(39-41)$ & $\mathrm{p}=0.49$ \\
\hline Pre-pregnant BW (kg) & $157.0(154.8-161.0)$ & $158.0(154.0-162.0)$ \\
\hline Pre-pregnant BMI (kg/m²) & $50.0(46.8-58.0)$ & $52.5(49.0-61.3)$ & $\mathrm{p}=0.08$ \\
\hline BW (kg) & $20.4(19.1-22.6)$ & $21.2(19.5-24.6)$ & $\mathrm{p}<0.05$ \\
\hline BMI(kg/m²) & $61.0(54.8-67.0)$ & $64.0(58.0-75.0)$ & $\mathrm{p}<0.05$ \\
\hline BMI $\geq 25$ & $25.0(22.0-26.3)$ & $25.0(23.8-30.0)$ & $\mathrm{p}=0.11$ \\
\hline Maternal GBS status positive & $7[9.5]$ & $41[70.7]$ & $\mathrm{p}=0.36$ \\
\hline GBS (missing) & $4[5.4]$ & $3[5.2]$ & $\mathrm{p}=0.47$ \\
\hline & & $5[8.6]$ & \\
\hline Continuous variables are presented as median with (interquartile range). & \\
\hline BW: body weight. BMl: body mass index. GBS: Group B Streptococcus. & \\
\hline
\end{tabular}

Table 1 shows the baseline characteristics of the study population. Among them, the median age was 36 years, and the median BMI was $25.0 \mathrm{~kg} / \mathrm{m}^{2}$. The median gestational age was 40 weeks. Parous women were 5 parturients, and the women with maternal Group B Streptococcus (GBS) status positive were 10 parturients. Among them, 58 (43.9\%) were confirmed to fulfill the criteria of CAM. Pre-pregnant body weight (BW), current BW, and BMI are significantly higher in CAM (+) than in CAM (-).

Table 2. Anesthetic management of epidural labor analgesia of the study population 


\begin{tabular}{|c|c|c|c|}
\hline Table 2 & & & \\
\hline & CAM (-) & CAM $(+)$ & $p$ value \\
\hline & $\mathrm{n}=74$ & $\mathrm{n}=58$ & \\
\hline Induction technique of labor analgesia & & & $p=1.00$ \\
\hline CSEA & 64 [86.5] & 49 [84.5] & \\
\hline DPE & $7[9.5]$ & 6 [10.3] & \\
\hline EPI & $3[4.1]$ & $3[5.2]$ & \\
\hline Duration of epidural labor analgesia (hr) & $8.0(4.5-14.0)$ & $11.5(6.0-19.0)$ & $p<0.05$ \\
\hline$<10$ & $45[60.8]$ & $25[43.1]$ & \\
\hline 10 to $<20$ & $17[23.0]$ & 20 [34.5] & \\
\hline 20 to $<30$ & 7 [9.5] & 8 [13.8] & \\
\hline 30 to $<40$ & $3[4.1]$ & $5[8.6]$ & \\
\hline$\geq 40$ & 2 [2.7] & $0[0.0]$ & \\
\hline Cesarean delivery & & & \\
\hline Decision-to-delivery time (min) & $56.5(41.0-72.5)$ & $73.0(60.0-90.5)$ & $p<0.05$ \\
\hline Operation time (min) & $45.5(39.0-56.0)$ & $52.4(42.8-70.3)$ & $p<0.05$ \\
\hline $\begin{array}{l}\text { Continuous variables are presented as } \mathrm{m} \\
\text { Categorical variables are presented as nu }\end{array}$ & $\begin{array}{l}\text { dian with (interqua } \\
\text { aber [\%] }\end{array}$ & tile range). & \\
\hline CSEA: combined spinal and epidural ana & esia. DPE: dural $p$ & ncture epidural an & gesia. \\
\hline EPI: epidural labor analgesia. & & & \\
\hline
\end{tabular}

Table 2 shows the anesthetic management of epidural labor analgesia of the study population. CSEA was the analgesic method in $86.0 \%$ (113 parturients). Among them, the median duration of epidural labor analgesia was $8.0 \mathrm{~h}$ (interquartile range (IQR); 5.0-17.0). The duration of epidural labor analgesia was significantly longer in CAM (+) than in CAM (-) $(11.5 \mathrm{~h}$ vs. $8.0 \mathrm{~h})$. Decision-to-delivery time was defined as the duration from deciding on a cesarean delivery to the delivery time. Decision-to-delivery time was significantly longer in CAM (+) than in CAM (-).

\section{Primary outcome}

Table 3. Primary outcome; failure rate of epidural conversion 
Table 3

Failure rate of epidural conversion Crude odds ratio p value $(95 \% \mathrm{Cl})$

$\begin{array}{llll}\text { CAM (-) } & 14 / 74(18.9 \%) & \text { ref. } & - \\ \text { CAM }(+) & 27 / 58(46.6 \%) & 3.7(1.7-8.3) & p<0.001\end{array}$

Failure rate of epidural conversion is shown in Table 3. The failure rate in CAM (+) group was $46.6 \%$, which was significantly higher than that in CAM (-) group of $18.9 \%$ (crude OR $3.7,95 \% \mathrm{Cl} 1.7-8.3, \mathrm{p}<$ $0.001)$. In the CSEA subgroup analysis, the failure rate in CAM (+) group was also significantly higher than that in CAM (-) group (crude OR $=3.4,95 \% \mathrm{Cl} 1.5-7.8, \mathrm{p}<0.05$, Additional Table 2).

Table 4. Primary outcome; multivariable logistic regression analysis

\begin{tabular}{|lcl|}
\hline Table 4 & & \\
& $\begin{array}{c}\text { Adjusted odds ratio } \\
(95 \% \mathrm{Cl})\end{array}$ & $\mathrm{p}$ value \\
\hline CAM & $3.6(1.6-8.4)$ & $\mathrm{p}<0.05$ \\
\hline Age & $1.9(0.8-4.9)$ & $\mathrm{p}=0.13$ \\
\hline BMI & $0.9(0.4-2.3)$ & $\mathrm{p}=0.88$ \\
\hline Multiparous woman & $0.6(0.0-4.9)$ & $\mathrm{p}=0.69$ \\
\hline Duration of epidural labor analgesia & $1.8(1.2-2.7)$ & $\mathrm{p}<0.05$ \\
\hline & & \\
\hline Age was adjusted for categorical variable $(<35 ; 35$ to $<45 ; \geq 45)$ & \\
\hline BMI was adjusted for categorical variable $(<25 ; \geq 25)$ & \\
\hline $\begin{array}{l}\text { Duration of epidural labor analgesia was adjusted for categorical variable } \\
(<10 ; 10 \text { to }<20 ; 20 \text { to }<30 ; 30 \text { to }<40 ; \geq 40)\end{array}$ & \\
\hline
\end{tabular}

After adjusting for potential confounders, CAM was associated with failure of epidural conversion to cesarean delivery anesthesia (adjusted $\mathrm{OR}=3.6,95 \% \mathrm{Cl} 1.6-8.4, \mathrm{p}<0.05$, Table 4). A longer duration of epidural labor analgesia was associated with failure of anesthesia for cesarean section (adjusted OR = $1.8,95 \% \mathrm{Cl} 1.2-2.7, \mathrm{p}<0.05)$. In the CSEA subgroup analysis, CAM was again associated with anesthetic failure (adjusted $\mathrm{OR}=3.4,95 \% \mathrm{Cl} 1.5-8.2, \mathrm{p}<0.05$, Additional Table 2). 
Secondary outcomes

Table 5. Secondary outcomes; quality of epidural labor analgesia

\begin{tabular}{|llll|}
\hline & CAM (-) & CAM (+) & $p$ value \\
\hline The number of PCEA request & $13.0(6.0-30.5)$ & $23.5(8.0-41.5)$ & $p=0.06$ \\
\hline The number of PCEA bolus & $10.5(5.8-22.0)$ & $18.5(7.0-34.0)$ & $p<0.05$ \\
\hline $\begin{array}{l}\text { Hourly consumption of } \\
\text { PCEA solution (ml/h) }\end{array}$ & $6.8(5.0-8.8)$ & $7.9(6.2-10.8)$ & $p<0.05$ \\
\hline $\begin{array}{l}\text { The number of rescue by anesthesiologist* } \\
\text { Intervertebral range of }\end{array}$ & $6(0-1)[0,4]$ & $0(0-2)[0,10]$ & $p<0.05$ \\
\hline 'loss of cold' level & $6(5-8)$ & $p=0.67$ \\
\hline $\begin{array}{l}\text { Continuous variables are presented as median with (Interquartile range). } \\
\text { * presented as a range with [ minimum, maximum] } \\
\text { PCEA: patient-controlled epidural analgesia. }\end{array}$ & & \\
\hline
\end{tabular}

The results of the secondary outcomes are shown in Table 5. Among the study population, the median number of PCEA requests was 17.0. The median number of PCEA boluses was 12.0. The median amount of local anesthetics used per hour was $7.4 \mathrm{ml} / \mathrm{h}$. The median number of intervertebral 'loss of cold' level was 6 . The parturient in CAM (+) group tended to push the PCEA button more often and received significantly more PCEA boluses, rescue doses by anesthesiologists, and the hourly amount of local anesthetics. At the same time, there was no significant difference in the 'loss of cold' levels in both groups (Table 5). CSEA subgroup analysis showed similar trends (Additional Table 3).

\section{Discussion}

In this retrospective cohort study, we examined the association between CAM and failed conversion of epidural labor analgesia to cesarean delivery anesthesia, and found that CAM is associated with higher failure rates after adjusting potential confounders. In the secondary outcomes, parturients with CAM needed significantly more local anesthetics for epidural labor analgesia. To our knowledge, this is the first study demonstrating such an association.

Until today, the risk factors of failed conversion of epidural labor analgesia to cesarean delivery anesthesia have been widely studied. Maternal factors such as young age [4], height (over $167 \mathrm{~cm}$ ) [5], higher BMI and weight [4], and greater gestational age [4]; factors of analgesia such as the number of episodes of breakthrough pain $[4,6,7]$ and required boluses of analgesics, duration of labor analgesia [7], urgency of cesarean delivery [8]; and anesthetic factors such as epidural analgesia alone [7] and 
nonobstetric anesthesiologists controlling labor analgesia $[6,9]$ have been implicated in the failure of epidural conversions. Of these factors, the most critical were "initiation of neuraxial labor analgesia by nonobstetric anesthesiologists", "additional epidural boluses", and "urgency of cesarean delivery" $[3,10]$. However, maternal infection during labor has not been considered as a risk factor.

The rate of failed conversion of epidural labor analgesia to cesarean delivery anesthesia has also been widely studied. The Royal College of Anesthetists in the United Kingdom recommends a threshold of $<1 \%$ conversion of neuraxial anesthesia to general anesthesia in elective cesarean deliveries and a threshold of $<5 \%$ for emergency deliveries [14]. In the previous studies, the ratio of conversion of neuraxial anesthesia to general anesthesia has been reported to be about 2.1-4.4\% [3]. The higher failure rates we demonstrated in this study (18.9\% in the CAM (-) and $46.6 \%$ CAM (+) groups) can be accounted for by our much stricter criteria of failure, which not limited to conversion to general anesthesia but included any use of drugs other than epidural local anesthetics. It should be noted that the rate of conversion to general anesthesia in this study was $1.7 \%$ (data not shown) in CAM (+) group and $1.4 \%$ (data not shown) in CAM (-) group, both of which were within the range of conversion rates reported by others $[3,14]$.

The secondary outcome in this study showed that parturients with CAM (+) were also more likely to feel strong pain during labor analgesia, which is consistent with our primary outcome. Moreover, this result is also consistent with one of the risk factors of failed conversion of epidural labor analgesia to cesarean delivery anesthesia, "additional epidural boluses", that the result of previous studies showed [3].

The ratio of CAM among patients requiring cesarean section in this study was also high. We defined CAM $(+)$ as the suspected Triple I, not as confirmed Triple I. In order to make a definitive diagnosis of CAM (confirmed Triple I), Triple I should be accompanied by objective laboratory findings of infection in amniotic fluid or histopathological evidence of infection or inflammation or both in the placenta, fetal membranes or the umbilical cord vessels (Additional Table 1) [13]. Clinical decision making should be considered before confirmed Triple I criteria are met. Therefore, we decided to use the suspected Triple I criteria. However, one of the limitations in this study is that some cases could not be diagnosed using the confirmed Triple I criteria because histopathological or culture tests were not performed.

The association between CAM and failure of epidural conversion may be explained as follows. Firstly, the increased labor pain in a parturient with CAM may be explained by previous reports that indicate that CAM causes uterine tenderness $[15,16]$ and that inflammatory mediators such as TNFa released by this inflammation contribute to the severe pain [17]. Secondly, it may be explained by the attenuated effects of local anesthetics under inflammation [18]. Thirdly, it may be explained by increased metabolism of local anesthetics or washout of local anesthetics by increasing blood flow in the hyperthermia. Further study is needed to understand the mechanism behind the association.

There was a significant difference between both groups in the duration of epidural labor analgesia and also the decision-to-delivery time. Although our study design does not allow any firm conclusion to be made regarding the mechanisms of these differences, we speculate that the longer duration of epidural labor analgesia in the CAM (+) group may be because parturients with CAM might have requested the 
induction of epidural labor analgesia in the earlier stage because of uterine tenderness. The longer decision-to-delivery time may indicate the lesser urgency for cesarean section in the CAM (+) group.

There are several limitations to this study. First, individual anesthesiologists used their discretion to provide anesthesia for cesarean section after assessing the efficacy of the epidural catheter. Patients had to be excluded if local anesthetics were not given via the catheter. Second, there are several potential sources of bias in this study. This study was conducted at a single-center with a high proportion of elderly primigravida women and that of parturients with CAM, which could have resulted in a selection bias. Third, some of the enrolled parturients did not undergo blood sampling while febrile because of which CAM may have been misdiagnosed.

\section{Conclusion}

This retrospective cohort study showed that CAM is associated with failure of anesthesia for cesarean sections via the epidural catheter. Further research is needed to understand its effects and the mechanism by which it diminishes the efficacy of epidural anesthesia.

\section{Abbreviations}

BMI: Body mass index; BW: Body weight; CAM: Chorioamnionitis; CSEA: Combined spinal and epidural anesthesia; Cl: Confidence interval; DPE: Dural puncture epidural; EPI: Epidural anesthesia; GBS: Group B Streptococcus; IQR: Interquartile range; PCEA: Patient-controlled epidural analgesia

\section{Declarations}

\section{Acknowledgements}

None.

\section{Authors' contributions}

Data acquisition: YK; Analysis and interpretation: YK, YN, TG, HS; Drafting of the manuscript for important content: YK, YN, TG, HS

All authors read and approved the manuscript.

\section{Funding}

This research did not receive any specific grant from funding agencies in the public, commercial, or notfor-profit sectors.

\section{Availability of data and materials}


Unfortunately, we do not have permissions to share these data. However, we would be happy to collaborate with requests from individual research groups would like to access our raw data. Please contact the corresponding author for information.

\section{Ethics approval and consent to participate}

This study was approved by the ethics committee of Juntendo Hospital (18-223).

All patients had written information and verbal consent to participate.

\section{Consent for publication}

Not applicable.

\section{Competing interests}

The authors declared no potential conflicts of interest with respect to the research.

\section{Author details}

a Department of Anesthesiology and Critical Care Medicine, Yokohama City University Hospital, 3-9 Fukuura, Kanazawa-ku, Yokohama 236-0004, Kanagawa, Japan

b Department of Anesthesiology, Juntendo University Hospital, 3-1-3 Hongo, Bunkyo-ku, Tokyo 113-8431, Japan

\section{References}

1. Butwick AJ, Bentley J, Wong CA, Snowden JM, Sun E, Guo N. United States state-level variation in the use of neuraxial analgesia during labor for pregnant women. JAMA Netw Open. 2018;1(8):e186567 [doi: 10.1001/jamanetworkopen.2018.6567].

2. Anim-Somuah M, Smyth RM, Cyna AM, Cuthbert A. Epidural versus non-epidural or no analgesia for pain management in labour. Cochrane Database Syst Rev. 2018;5:CD000331 [doi:

10.1002/14651858.CD000331.pub4].

3. Mankowitz SK, Gonzalez Fiol A, Smiley R. Failure to extend epidural labor analgesia for cesarean delivery anesthesia: A focused review. Anesth Analg. 2016;123(5):1174-80 [doi: 10.1213/ANE.0000000000001437].

4. Orbach-Zinger S, Friedman L, Avramovich A, llgiaeva N, Orvieto R, Sulkes J, Eidelman LA. Risk factors for failure to extend labor epidural analgesia to epidural anesthesia for cesarean section. Acta anaesthesiol Scand. 2006;50(8):1014-8 [doi: 10.1111/j.1399-6576.2006.01095.x].

5. Halpern SH, Soliman A, Yee J, Angle P, loscovich A. Conversion of epidural labour analgesia to anaesthesia for caesarean section: A prospective study of the incidence and determinants of failure. Br J Anaesth. 2009;102(2):240-3 [doi: 10.1093/bja/aen352]. 
6. Campbell DC, Tran T. Conversion of epidural labour analgesia to epidural anesthesia for intrapartum cesarean delivery. Can J Anaesth. 2009;56(1):19-26 [doi: 10.1007/s12630-008-9004-7].

7. Lee S, Lew E, Lim Y, Sia AT. Failure of augmentation of labor epidural analgesia for intrapartum cesarean delivery: A retrospective review. Anesth Analg. 2009;108(1):252-4 [doi: 10.1213/ane.0b013e3181900260].

8. Kinsella SM. A prospective audit of regional anaesthesia failure in 5080 caesarean sections. Anaesthesia. 2008;63(8):822-32 [doi: 10.1111/j.1365-2044.2008.05499.x].

9. Riley ET, Papasin J. Epidural catheter function during labor predicts anesthetic efficacy for subsequent cesarean delivery. Int J Obstet Anesth. 2002;11(2):81-4 [doi: 10.1054/ijoa.2001.0927].

10. Bauer ME, Kountanis JA, Tsen LC, Greenfield ML, Mhyre JM. Risk factors for failed conversion of labor epidural analgesia to cesarean delivery anesthesia: A systematic review and meta-analysis of observational trials. Int J Obstet Anesth. 2012;21(4):294-309 [doi: 10.1016/j.ijoa.2012.05.007].

11. National Collaborating Centre for Ws, Children's H. National Institute for Health and Clinical Excellence. Guidance. Caesarean section. National Institute for Health and Clinical Excellence: Guidance. London: RCOG Press.

National Collaborating Centre for Women's and Children's Health.; 2011.

12. Chau A, Bibbo C, Huang CC, Elterman KG, Cappiello EC, Robinson JN, Tsen LC. Dural puncture epidural technique improves labor analgesia quality with fewer side effects compared with epidural and combined spinal epidural techniques: A randomized clinical trial. Anesth Analg. 2017;124(2):560-9 [doi: 10.1213/ANE.0000000000001798].

13. Higgins RD, Saade G, Polin RA, Grobman WA, Buhimschi IA, Watterberg K, et al. Evaluation and management of women and newborns with a maternal diagnosis of chorioamnionitis: Summary of a workshop. Obstet Gynecol. 2016;127(3):426-36 [doi: 10.1097/AOG.0000000000001246].

14. Cesarean section anesthesia: technique and failure rate. In: Colvin JR, Peden CJ ed. Raising the Standard: a compendium of audit recipes for continuous quality improvement in anaesthesia. $3 \mathrm{ed}$. London: Royal College of Anesthetists, 2012: 220.

15. Suzuki S. Association between clinical chorioamnionitis and histological funisitis at term. J Neonatal Perinatal Med. 2019;12(1):37-40 [doi: 10.3233/NPM-17155].

16. Burke C, Chin EG. Chorioamnionitis at term: Definition, diagnosis, and implications for practice. J Perinat Neonatal Nurs. 2016;30(2):106-14 [doi: 10.1097/JPN.0000000000000163].

17. Ji RR, Xu ZZ, Gao YJ. Emerging targets in neuroinflammation-driven chronic pain. Nat Rev Drug Discov. 2014;13(7):533-48 [doi: 10.1038/nrd4334].

18. Keiser KMHK. Local anesthetic failure in endodontics: Mechanisms and Management. Endodontic Topics. 2002;:':26-39.

\section{Figures}


Figure 1

\section{Eligible parturients $n=180$}

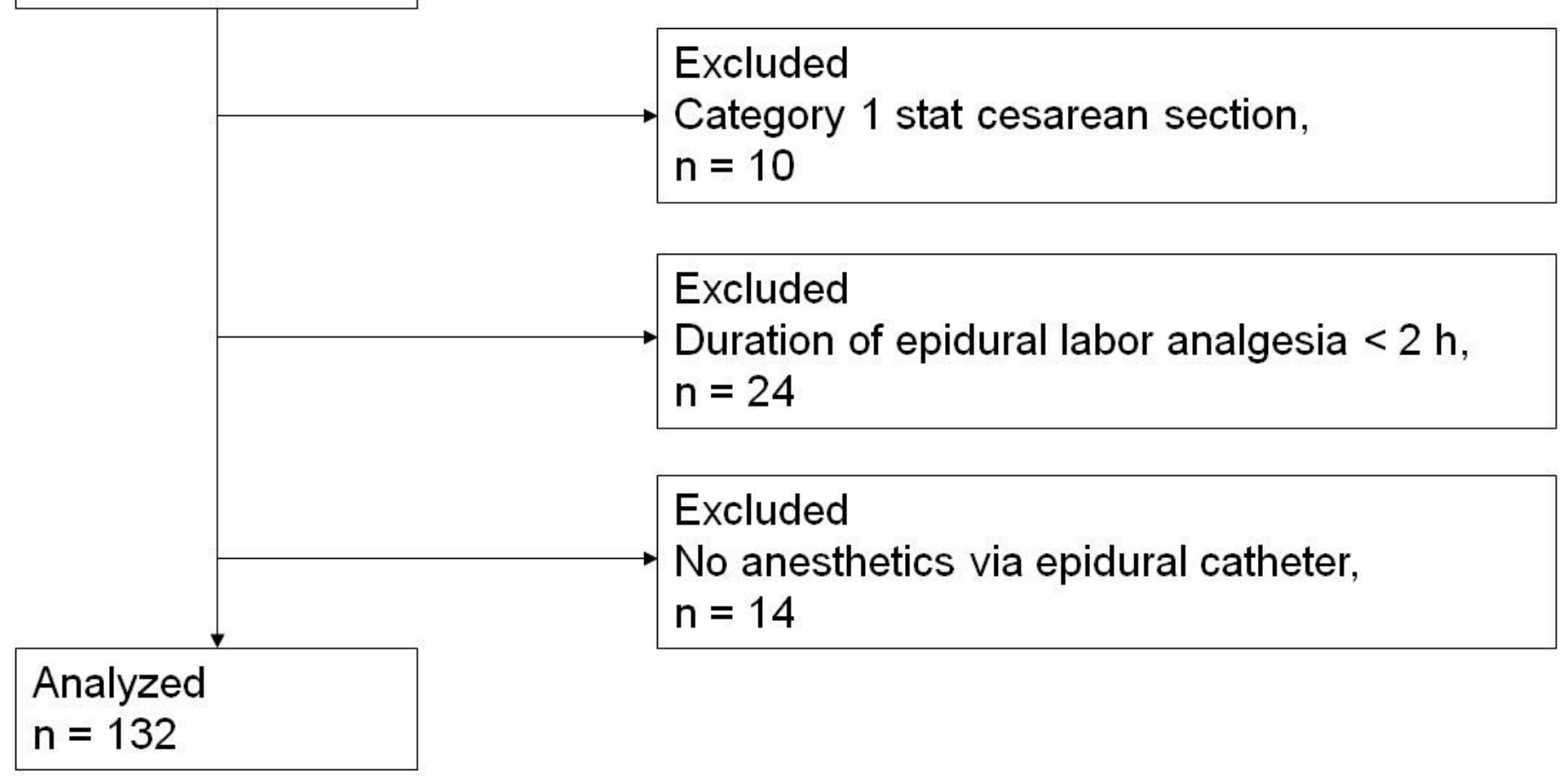

Figure 1

Study flow chart.

\section{Supplementary Files}

This is a list of supplementary files associated with this preprint. Click to download.

- 20200802Additionaltable3.xlsx

- 20200802Additionaltable2.xlsx

- 20200802Additionaltable1.xlsx 